\title{
Improving New Hire Turnover Through The Use Of Assessment Tools
}

Hassan Pordeli, Jacksonville University, USA

Mohamad Sepehri, Jacksonville University, USA

Russell Baker, Jacksonville University, USA

Tom Burke, MPS Group, USA

\begin{abstract}
This study focuses on one organization's adoption and use of a specific job matching assessment instrument for all of their hiring decisions over a three-year period. The paper examines the effectiveness of the organization's hiring assessment tool as a process for reducing their new hire turnover. The results of the study shows a significant improvement (reduction) in the new hire turnover, compared with the previous three-year period without utilizing the tool. These findings are consistent with years of empirical research on personality, consisting of characteristics behavior measurements that predict how an individual behavior in various situations (Greenberg, 1980).
\end{abstract}

Keywords: PXT Assessment Instrument, Behavioral Trait, Thinking Styles, Occupational Interest, Coefficient Alpha, Construct Validity

\section{INTRODUCTION}

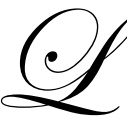
ooking for new hires and finding the right candidates with suitable skills and appropriate professional experience has always been a challenging experience for the recruiters and the HR departments. However, organizations are increasingly facing the challenge of finding the people who not only are best qualified for the job but also are a good fit for the organization. As the organizations realize the cost of poor hiring choices, workforce planning has become an integrated and a critical element of business strategy for many companies (Nass, 2002).

In recent years, there has been a shift from hiring people simply to fill positions to finding new hires who not only posses the proper job skills and job knowledge, but also the attitude and personal attributes necessary to succeed and contribute to the organization's success (Coleman, 2007). Many companies are now trying to find the right fit when hiring a new person, recognizing the difference between candidate with good experience and a good hire.

In their efforts to find the suitable new hires, business reliance on assessment tools to screen the applicants is increasing. There are varieties of assessment tools available to help companies to find the right match. When organizations develop the job description and the general framework for a particular job, assessment tools help to identify how an individual and the job may match (Ballantyne, 2004). The basic precept shared by all assessment tools is applicant evaluation using available comparative data from successful people engaged in the same type of occupation (Coleman, 2007).

\section{USING THE ASSESSMENT TOOLS FOR PERSONNEL SELECTION}

As stated previously, companies are increasingly recognizing the importance of the good match between the organization and the candidates they would like to hire. Most companies follow the conventional process of (a) defining the job and (b) establishing the required qualifications for the job. However, any successful hiring requires another step in the process: (c) job-matching process to ensure that the candidate would succeed within the 
organization (Greenburg, 2004). That is why job demand analyses (JDA) now utilize additional tools to include behavioral and cognition demand aspects of the job (Manville, 2005).

Burkholder (2003) underlines the significance of hiring candidates who can adjust and grow within the company. He put forward two questions regarding individual growth: (1) within the job role and (2) within the company. The organizations would face turnover and depletion of valuable and talented human resources if the answer to any of the questions is negative. However, appropriate and relevant employee pre-screening assessment has shown a substantial reduction in employee turnover by 25 to 45 percent (Spherion, 2002). The Spherion study revealed that those candidates who matched best for the job, had much lower turnover rate (18 percent) than those who had marginal match (turnover of 57 percent) or poor match (turnover of 69 percent).

\section{BACKGROUND OF THE STUDY}

This study focuses on the North American division of mIT, a global provider of IT staffing and consulting solutions. mIT serves more than 1,000 clients and generates close to $\$ 1$ billion in annual revenues. Much of their success is based heavily on the effectiveness of a large cadre of IT recruiters within their 40 branch office network throughout the U.S. and Canada.

The challenge for mIT and other staffing organizations is that good recruiters are not easy to find. There is no formal college degree or education specialty for recruiters. Most recruiters come out of traditional careers within the same industries for which they will ultimately recruit (Dooney, 2006). For example, many accounting and finance recruiters are CPA's and most legal staff recruiters are either ex-lawyers or paralegals. The IT industry is no different, which creates a problem for many hiring managers in search of good IT recruiters. Companies want their IT recruiters to have industry experience; however the personality characteristics or behavioral traits of an IT program developer may be quite different from that of a successful IT recruiter. Therefore, getting the correct match of the right person for the right recruiting job is a key success factor for mIT hiring managers.

Most companies recruit and select job candidates based on their knowledge and related skills of a particular position opening. The best companies also look at a candidate's fit to the position and the organization in which they will work. To select the best employees, hiring managers need to effectively assess a candidate's fit to the predetermined behaviors which have been found to be most successful within the job they are seeking to fill (Swenson, 1994). In 2003, mIT recognized the need to improve its hiring selection process for IT recruiters, due to the significant high rate of turnover for new hire recruiters within their first year of employment. Over a three year period from January 2001 to December 2003, mIT's turnover for newly hired recruiters was over 20\% within their first 3 months of employment; 35\% within their first 6 months; and $45 \%$ for their first 12 months.

mIT researched several hiring assessment vendors and selected the Profile XT (PXT) instrument from Profiles International, a leading provider of on-line assessment tools. The PXT instrument is based on studies derived from the Personality Surveys PS-I and PS-II in addition to internal Profiles International work with the PXT.

In January 2004, mIT incorporated the PXT assessment instrument into their existing new hire recruiting and selection process, as shown below. 


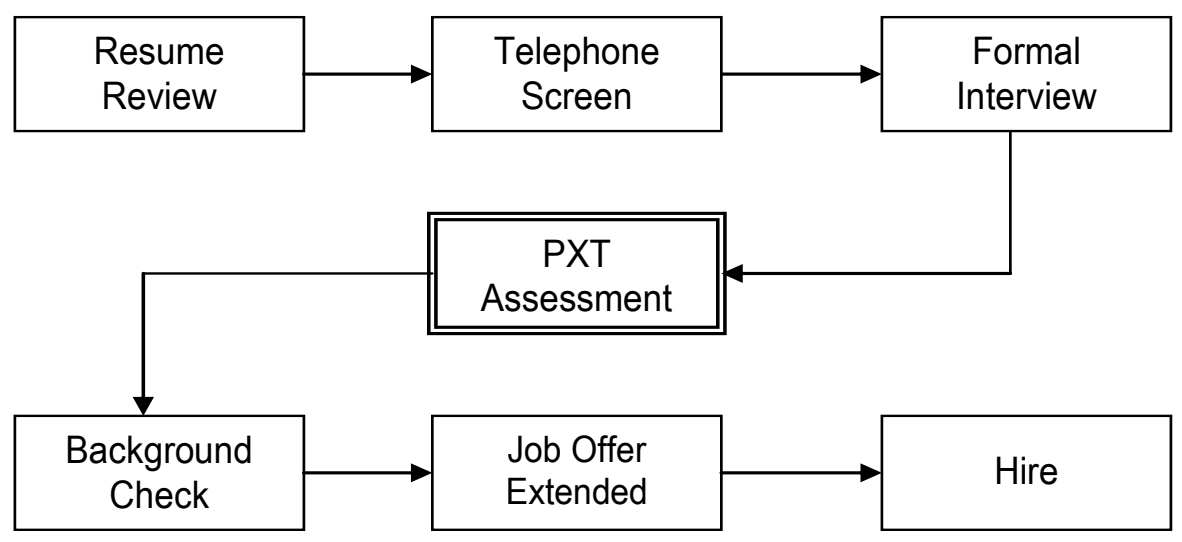

In using any personality assessment tool in personnel selection, many questions and concerns regarding the validity and/or reliability of the instrument need to be addressed (Rudder, 1999). Among many recommendations, Rudder suggests that we should understand (a) the theoretical framework of personality on which the assessment instrument is based on, (b) the personality profile used to distinguish the best-match job applicants, and (c) the behavioral traits that are defined and used by the instrument.

The authors would note that this study is not an endorsement of the PXT Assessment Instrument. There are a variety of personnel assessment instruments available in the marketplace. The PXT Assessment Instrument is the tool used by mIT and consequently is the instrument evaluated herein. The following will help to provide an understanding of the PXT Assessment Instrument, the behavioral traits on which it is based, and the definition of each trait.

\section{PXT Assessment Instrument}

The PXT instrument evaluates several personality characteristics as a part of its assessment of jobcandidate fit. These attributes are based on a various constructs measured across a ten-point scale. "The theme of the PXT scales lies in Cognitive Psychology. Conclusions about unobservable cognitive processes can often be drawn from objective, methodical observations of behavior. The act of reporting one's behavior is a reflection of the total person within, which partially determines one's fit for a number of work environments" (Profiles International, 2006).

PXT uses multiple scales to determine a validate job fit. These scales measure different job competencies in multiple ways. This provides the data necessary to develop a needed job match pattern. By standardizing the job fit process, Job Match Patterns more accurately predict job fit than do individual scores. mIT constructed a job match pattern for recruiters by assessing and examining the score patterns of their top 50 performing recruiters. The resulting scores serve as the basis for mIT's job matching analysis.

The following is a brief description of the personality characteristics evaluated by the PXT assessment instrument (direct quotation, quotation marks omitted - Profiles International, 2001):

\section{Behavioral Traits}

- $\quad$ Accommodating is often associated with a concern for group accountability. A willingness to consider the needs of all group members is typical.

- $\quad$ Assertiveness is identifiable as a measure of generalized confidence. It is often associated with expressed influence.

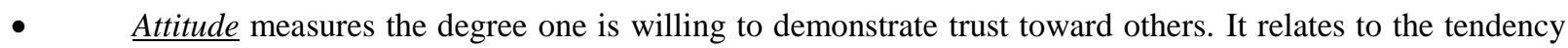
to suspend judgments about people and outcomes. 
- $\quad$ Energy Level demonstrates a tendency toward restlessness, activity, and drive. This scale deals with issues such as efficiency and time utilization.

- $\quad$ Independence defines the manner in which an individual prefers to be directed by others, and one's potential to accomplish tasks with minimal supervision.

- $\quad$ Objective Judgment is the willingness to make use of reason and logic more than intuition. This is often referred to as the balance between "head" and "gut."

- $\quad$ Sociability can be seen as a measure of one's reliance upon interpersonal contacts and work that involves group-oriented endeavors.

- Manageability suggests a strong relationship to social responsibility. It's a measure of how one reacts to the limits placed by authority and one's acceptance of conventional opinion.

- Decisiveness reflects how confident one is in accepting the risk of making a decision in a timely fashion.

\section{Thinking Styles}

- $\quad$ Verbal Skill is a measure of verbal skill through vocabulary.

- $\quad$ Verbal Reasoning is using words as a basis in reasoning and problem solving.

- $\quad$ Numerical Ability is a measure of numeric calculation ability.

- $\quad$ Numeric Reasoning is using numbers as a basis in reasoning and analysis.

\section{Occupational Interests}

- $\quad$ Enterprising indicates an interest in occupations where one uses persuasiveness and enjoys presenting plans. The entrepreneurial aspects of sales and business are often desirable for such individuals.

- $\quad$ Financial/Administrative indicates interest in occupations that work with financial data, business systems, administrative procedures, etc.

- $\quad$ The People Service scale indicates interest in occupations that help people and are concerned with the welfare of others.

- The Technical scale indicates interest in occupations that center on scientific and technical activities, research, and intellectual skills.

- The Mechanical scale indicates interest in occupations that involve hands-on work, using equipment and machinery, and physical vocations.

- $\quad$ The Creative scale indicates interest in occupations where one may be imaginative, original, and aesthetic.

The roots of the PXT go back twenty-five years. More than 200,000 job applicants and employees representing a diverse population participated instrument development. Profiles International has conducted years of statistical analyses on the internal and external validity of the PXT assessment instrument.

Overall, the results of their analyses consistently indicate that the PXT is a valid measure of the dimensions of normal adult personality characteristics. Measurement of these characteristics is useful in predicting behavior related to important business-related criteria, (Profiles International).

\section{Descriptive Statistics - Raw Scores}

The following statistical information is provided by Profiles International in support of their PXT assessment instrument's reliability and validity. The table below summarizes the descriptive statistics for the PXT Behavioral Traits. Their sample (n) will continue to increase over time, so the data produced by this assessment instrument will constantly solidify in its reliability and applicability (Profiles International). 


\begin{tabular}{|l|l|l|l|l|l|l|l|l|l|}
\hline n=206,443 & DECIS & ENERG & ASSER & SOCIA & MANAG & ATTIT & ACCOM & INDEP & OBJ.J \\
\hline Mean & 9.43 & 10.91 & 17.14 & 18.04 & 17.35 & 18.66 & 17.49 & 11.76 & 16.16 \\
\hline Std. Error & .0079 & .0087 & .0104 & .0117 & .0094 & .0104 & .0088 & .0112 & .0092 \\
\hline Std. Dev. & 3.57 & 3.95 & 4.73 & 5.32 & 4.25 & 4.70 & 4.01 & 5.11 & 4.16 \\
\hline Minimum & 0 & 0 & 0 & 0 & 0 & 0 & 0 & 0 & 0 \\
\hline Maximum & 16 & 21 & 27 & 26 & 25 & 26 & 26 & 25 & 24 \\
\hline
\end{tabular}

\section{Coefficient Alpha Reliability Analysis}

Reliability refers to the consistency of test items as selected by test-takers, as well as the scores obtained when re-tested with the same assessment on different occasions. Since all types of reliability are concerned with the degree of consistency of test items, they can all be expressed in terms of a correlation coefficient. A correlation coefficient expresses the degree of relationship between two variables. Although no test is a perfectly reliable instrument, test reliability correlation coefficients should be .70 or higher (US Department of Labor, 1999).

The following table contains coefficient alpha reliabilities for the nine behavioral traits for a sample of job applicants and incumbents. Internal consistency of the PXT was determined by calculating coefficient alpha reliability. This analysis indicates that the nine behavioral traits are reliable and produce consistent results.

\begin{tabular}{|l|c|}
\hline Coefficient Alpha, PXT $\mathrm{n}=206,443$ & Coefficient Alpha \\
\hline PXT Scales & .77 \\
\hline Decisiveness & .75 \\
\hline Energy Level & .79 \\
\hline Assertiveness & .87 \\
\hline Sociability & .77 \\
\hline Manageability & .82 \\
\hline Attitude & .73 \\
\hline Accommodating & .83 \\
\hline Independence & .78 \\
\hline Objective Judgment & .79 \\
\hline Average & .79 \\
\hline
\end{tabular}

The alpha coefficients for the PXT range from a low of .73 for the Accommodating Scale, to a high of .87 for the Sociability Scale. While an average coefficient alpha is not always calculated, some consider it to be a useful summarization, and in this case averages to .79 for the PXT.

\section{Construct Validity}

Profiles International defines construct validity as "the extent to which an assessment and its scales are an accurate measure of a particular construct or trait. Construct validity determines how well the assessment measures what it was designed and purported to measure. Although there are different methods for evaluating construct validity, correlations should be consistent with expectations based on what these scales were intended to measure"(Profiles International). The PXT was designed to measure nine behavioral dimensions of normal personality. The following table contains the inter-scale correlations among the nine PXT behavioral traits (Profiles International). 


\begin{tabular}{|c|c|c|c|c|c|c|c|c|c|}
\hline \multicolumn{8}{|c|}{ PXT Inter-scale Correlations } & \multicolumn{2}{|c|}{$\mathrm{N}=206,443$} \\
\hline & Decis & Ener & Asser & Soci & Mana & Atti & Acco & Inde & ObjJ \\
\hline Decisiveness & 1 & $.805(* *)$ & .708(**) & $.280(* *)$ & $\begin{array}{l}- \\
.278(* *)\end{array}$ & $-.177(* *)$ & $\begin{array}{l}- \\
.478(* *)\end{array}$ & $.392(* *)$ & $-.104(* *)$ \\
\hline Energy Level & & 1 & $.403(* *)$ & $.097(* *)$ & $\begin{array}{l}- \\
-389(* *)\end{array}$ & $-.260(* *)$ & $.483(* *)$ & $.464(* *)$ & $-.247(* *)$ \\
\hline Assertiveness & & & 1 & $.427(* *)$ & $\begin{array}{l}- \\
.120(* *)\end{array}$ & $-.076(* *)$ & $\begin{array}{l}. \\
.439(* *)\end{array}$ & $.287(* *)$ & $.129(* *)$ \\
\hline Sociability & & & & 1 & $.213(* *)$ & $.214(* *)$ & $.022(* *)$ & $\begin{array}{l}. \\
.122(* *)\end{array}$ & $.198(* *)$ \\
\hline Manageability & & & & & 1 & $.676(* *)$ & $.650(* *)$ & $\begin{array}{l}- \\
.668(* *)\end{array}$ & $.607(* *)$ \\
\hline Attitude & & & & & & 1 & $.500(* *)$ & $.319(* *)$ & $.390(* *)$ \\
\hline $\begin{array}{l}\text { Accommo- } \\
\text { dating }\end{array}$ & & & & & & & 1 & $\begin{array}{l}. \\
.521(* *)\end{array}$ & $.355(* *)$ \\
\hline Independence & & & & & & & & 1 & $-.243(* *)$ \\
\hline $\begin{array}{l}\text { Objective } \\
\text { Judgment }\end{array}$ & & & & & & & & & 1 \\
\hline
\end{tabular}

\section{PURPOSE AND HYPOTHESES}

The purpose of this study is to determine whether or not mIT's use of their hiring assessment instrument, prior to hiring an employee, results in a meaningful reduction in the employee turnover rate within the first 3 months of employment. To answer this question, the following hypotheses were developed:

Null Hypothesis $\left(\mathbf{H}_{\mathbf{0}}\right)$ : Use of a hiring assessment instrument does $\boldsymbol{n o t}$ decrease new hire turnover rate within the first 3 months of employment.

Alternative Hypothesis $\left(\mathbf{H}_{\mathbf{a}}\right)$ : Use of a hiring assessment instrument does decrease new hire turnover rate within the first 3 months of employment.

(For these two hypotheses, data were collected from over 1,600 new hires within mIT's 40 branch offices within the U.S. and Canada between the years 2001 - 2006.)

\section{RESEARCH DESIGN \& METHODOLOGY}

Turnover data was collected from mIT for a period of 6 years beginning in January 2001 and ending in December 2006. For the period of January, 2001 through December, 2003, mIT did not use a hiring assessment instrument during the interview and selection process for their employees. From January, 2004 through December, 2006, the PXT hiring assessment instrument was developed and implemented as an integral step in mIT's selection process.

It is mIT's experience that new hire turnover related to job fit typically occurs within an individual's first 3 months of employment. Therefore new hire and termination dates from 1 to 3 months were collected for each of the 6 years studied. Relevant data from January, 2001 through December, 2003 was compared to January, 2004 through December, 2006 to determine if mIT's hiring assessment instrument made a statistical difference in the post implementation new hire turnover rate. Though other factors may also cause fluctuations in new hire turnover such as economic conditions, management effectiveness, work environment, etc., no evidence was found suggesting these items were significantly different over the study period. Therefore they are not factored into this study. 


\section{RESULTS}

A paired sample t-test was performed to determine if the treatment, utilizing the hiring assessment instrument, was effective in statistically reducing the new hire turnover rate within the first 3 months of employment. This type of test is used to determine if changes or treatments to an existing process or methodology statistically change the outcome even after accounting for sampling variations. The following are the three types of paired t-tests used for a normally distributed sample:

1. $\quad$ Test to determine if the treatment made any difference - this is a two-tailed t-test as results could either increase or decrease the original process.

2. $\quad$ Test to determine if the treatment increased the process - this is a one-tailed $\mathrm{t}$-test as a positive result can only occur in the right tail of the normal distribution curve.

3. $\quad$ Test to determine if the treatment decreased the process - this is also a one-tailed t-test as a positive result can only occur in the left tail of the normal distribution curve.

Since the objective of the assessment instrument is to reduce new hire turnover within the first 3 months of employment, the authors conducted a one-tailed paired t-test. The 9 months of results for the years $2004-2006$ were subtracted from the 9 months of results for the years $2001-2003$ creating a mean difference between the two sets of data to be 28 employees. The standard deviation of the difference was determined to be 24 employees.

The t-test statistic was then calculated as $\mathbf{- 3 . 0 9 6}$ using the following formula:

t-stat $=\left(\mathrm{d} /\left(\mathrm{s}_{\mathrm{d}} / \sqrt{\mathrm{n}}\right)\right)$ where:

$\mathbf{d}=$ average deviation between the 6 years

$\mathbf{s}_{\mathbf{d}}=$ the standard deviation of the 6 years

$\sqrt{ } \mathbf{n}=$ the square root of the number of observations

Using an alpha of $\mathbf{0 1}$ and $\mathbf{8}$ degrees of freedom on a one-tailed t-test, the t-critical statistic was calculated at $\mathbf{- 2 . 8 9 6}$. The results of the test are shown in the following table:

$\mathrm{Ho}_{0}$ Ud $>=0$ The assessment test were not effective

$\mathrm{Ha}$ : Ud $<0$ The assessment test were effective

Confidence level $=$ Alpha $=.01$

\begin{tabular}{|c|c|c|}
\hline $2004-2006$ & $2001-2003$ & Difference \\
\hline 11 & 27 & -16 \\
\hline 13 & 12 & 1 \\
\hline 11 & 15 & -4 \\
\hline 6 & 37 & -31 \\
\hline 10 & 21 & -11 \\
\hline 11 & 18 & -7 \\
\hline 16 & 23 & -7 \\
\hline 7 & 16 & -9 \\
\hline \multirow[t]{5}{*}{6} & 9 & -3 \\
\hline & Average (d) & -10 \\
\hline & Standard Deviation (Sd) & 9 \\
\hline & Tstat & -3.096 \\
\hline & Tcrtical (.01 and 8 DF) & -2.896 \\
\hline
\end{tabular}


Based on a normally distributed curve, the reject region is on the left side and begins at the critical point of -2.896. Any results to the right side of this point would cause the acceptance of the null hypothesis that the assessment instrument had no statistical influence on the turnover rate. The fluctuation could be explained by the inherent variation in the sampling methodology. However, the results for mIT lie within the reject region at $\mathbf{- 3 . 0 9 6}$ indicating that the decrease in the turnover rate is not due to sampling error but due to the implementation of the assessment instrument.

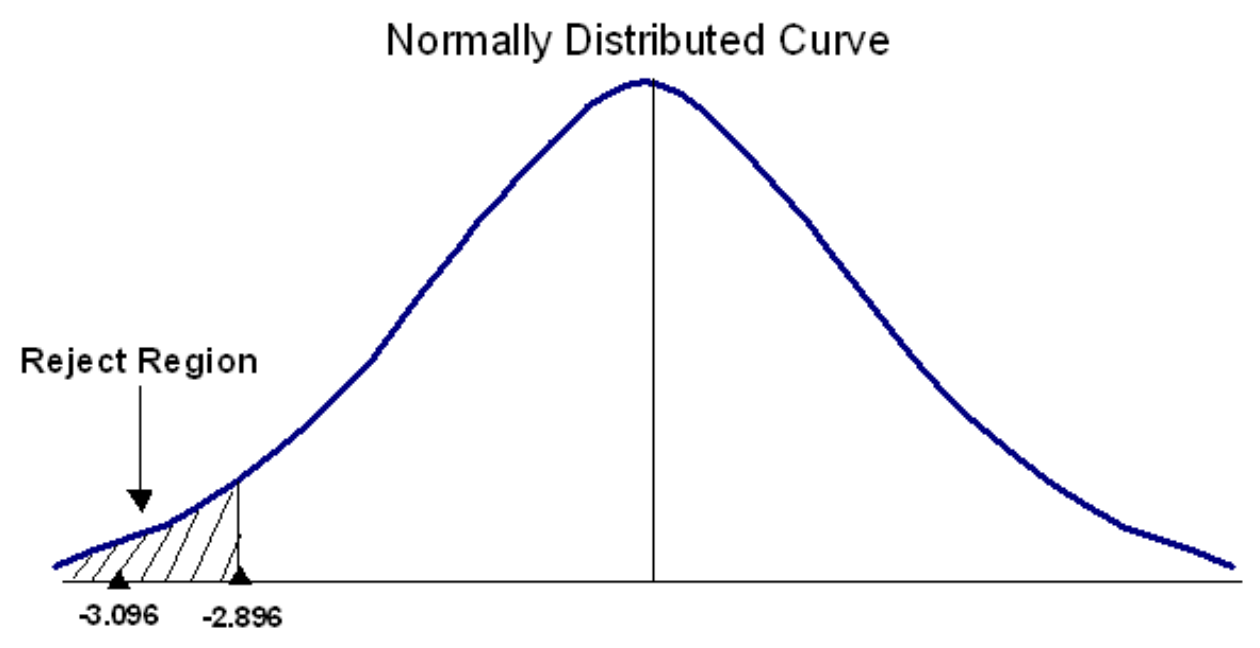

\section{CONCLUSION \& RECOMMENDATIONS}

Since the test statistic lies well outside of the critical range for a $99 \%$ confidence level, the null hypothesis must be rejected and a conclusion can be formed that the implementation of the hiring assessment instrument used by mIT did statistically decrease their new hire turnover rate associated with their first 3 months of employment. These findings support the empirical research conducted over the past two decades on the use of assessment tools in the recruitment and selection process of employees. However, this research paper studied new hire turnover within the first 3 months of employment. Further studies should be conducted to see what effects of new hire turnover exist beyond the 3 month period of employment.

It is recommended that mIT continue to monitor and measure the effectiveness of their hiring assessment instrument for new hires. Although they have experienced very positive results in the past 3 years, the true validation comes from the resulting performance of their new hires using this assessment tool in the long run. It is important for $\mathrm{mIT}$ to implement a standardized performance tracking system that enables them to gain quantifiable feedback regarding the degree of success they have attained from using their job matching process and hiring assessment instrument.

The authors cannot ascertain the extensibility of these results based on a single study from one organization. Other organizations using the PXT Assessment Instrument may be evaluated and their results compared with the mIT results to determine the extensibility of this research. Additionally, this same study process may be conducted based on other instruments.

In addition, it is recommended that further research be conducted on any adverse selection impact related to diversity of new hires. Although it is true that specific personality characteristics are more successful in certain jobs, there is also evidence that diversity in the workplace can enhance the quality of ideas and problems solving (Swenson). 
It is discussed herein that other factors may also cause fluctuations in new hire turnover such as economic conditions, management effectiveness, and work environment. Although no evidence was found suggesting these items were significantly different over the study period additional study should be conducted to determine if there exists a change in turnover rate during the same study period for organizations that did not implement a preemployment assessment instrument. This type of study could support (or refute) the non-effectiveness of other potentially mitigating factors.

Again, the authors reiterate that this study is not an endorsement of the PXT Assessment Instrument. There are a variety of personnel assessment instruments available in the marketplace. The PXT Assessment Instrument is the tool used by $\mathrm{mIT}$ and consequently is the instrument evaluated herein.

\section{AUTHOR INFORMATION}

Dr. Hassan Pordeli is a Professor of Economics and Finance. Pordeli joined the JU faculty in 1983. He served as Assistant to the Dean of the College of Business in 1992. He served as Interim Dean of the school for two years. Pordeli was appointed Dean of the College of Business from June 1995 to June 1996. He was named Prudential/JU Professor of the Year in 1993-1994. Pordeli holds a B.S in Industrial Management. He earned his M.A. and Ph.D. in economics from the University of Nebraska-Lincoln. Pordeli named one of the "20 Outstanding Young Men of America" in 1985 and has received the City of Jacksonville Award for Outstanding Contributions to the Community and Citizens of Jacksonville.

Dr. Mohamad Sepehri (Dr. Mo) is the Division Chair and professor of Management and International Business at Davis College of Business, Jacksonville University. He has a unique combination of academic and business experience, with extensive background in strategic management/leadership and broad experience in international and global business operations. Dr. Sepehri has extensive scholarly researches that have been presented at national as well as international forums. He has written numerous research papers that were published in professional and refereed journals. Dr. Sepehri has also been recognized by other professional and scholarly bodies. He has been acknowledged in the Journal of Operations Management (JOM) as an "outstanding contributor" on several occasions.

Dr. Russell Baker is an Associate Professor of Management Information Systems at Jacksonville University's Davis College of Business. His doctoral degree is in information systems management with a dual cognate in management from the University of Sarasota. He is currently a member of the Microsoft Dynamics Academic Advisory Council, past president and director of the Southern Association for Information Systems, and past director of the Florida Association of Teacher Educators. The author or coauthor of over seventy published manuscripts, he is the 2008-2009 Jacksonville University Professor of the Year and the recipient of the 2007-2008 Jacksonville University Scholar award.

Thomas M. Burke currently serves as senior vice president, human resource officer for MPS Group, Inc., a 2.5 billion dollar provider of staffing and consulting solutions in the disciplines of information technology, finance and accounting, law, engineering, and healthcare with operations throughout North America, Europe and Asia. Mr. Burke joined the NYSE company in August 2003. Prior to joining MPS Group, Mr. Burke held a number of human resource leadership positions, including his most recent role as director of global human resources for Deloitte \& Touche LLP. His human resources responsibilities at MPS Group include organizational development, employee relations, compensation, benefits, and corporate governance. Mr. Burke received a bachelor of business administration degree in Management from the University of North Florida and masters of business administration from Jacksonville University. He is a senior professional member of the society for human resource management and serves on a number of charitable and organizational boards.

\section{REFERENCES}

1. Ballantyne, Lain \& Povah, Nigel, Assessment and Development Centers, Grower Publishing, Ltd. (2004) 
2. Burkholder, Nicholas, et. al, On Staffing: Advice and Perspectives from HR Leaders, John Wiley and Sons (2003)

3. Coleman, Howard, Predicting Future Job Performance, Reed Business Information, Elsevier Inc. (2007)

4. Dooney, J. \& Victor, J., Recruiting Benchmarks: Defending and Improving Recruiting Performance. [Electronic version]. SHRM Research (2006).

5. $\quad$ Greenberg, Herbert, How to Hire and Develop Your Next Top Performer, John Wiley and Sons. (2004)

6. Greenberg, H.M. \& Greenburg, J., Job Matching for Better Sales Performance. Harvard Business Review, 58(5), 128-133 (1980).

7. Manville, Carolyn, Measuring Occupational Performance, SLACK Incorporated (2005).

8. $\quad$ Nass, Lisa, Are Assessment tools Right for You? Watson Wyatt her Practice (2002)

9. Profiles International, Inc., Employment Guide: Hiring and retaining Top Performing Employees. [Electronic version] (2001).

10. Profiles International, Inc. (2006). The ProfileXT Technical Manual. [Electronic version]. Descriptive Statistics. (3), 29-30.

11. Profiles International, Inc., The ProfileXT Technical Manual. [Electronic version]. The Construct Validity Approach. (3), 32-35 (2006).

12. Rudder, Carol and Truelson, Sara, Using Personality Assessment in Personnel Selection, Discover me Personality-Based Recruiting Services (1999).

13. Russell, C., Right Person-Right Job: Guess or Know: The Breakthrough Technologies of Performance Information. Johnson \& James Press (1996).

14. Spherion Recruiting, Staffing, and Workforce solutions (2002).

15. Swenson, A.T., The New Art of Hiring Smart: Matching the Right Person to the Right Job. [Electronic version]. International Institute of Marketing Excellence, Inc (1994)..

16. U.S. Department of Labor, Employment and Training Administration, Testing and Assessment: An Employer's Guide to Good Practices. Washington, DC: U.S. Government Printing Office (1999). 